\title{
Los derechos humanos de las personas jurídicas. Titularidad de derechos y legitimación en el sistema interamericano. Ignacio De Casas y Fernando Toller (2015). México: Editorial Porrúa
}

\author{
Héctor José Miguens \\ Universidad Austral - CONICET
}

La ex Relatora Especial sobre la Libertad de Expresión, Catalina Botero, expone en su prólogo a la obra la razón de ésta: que el sistema interamericano había formulado la "regla de exclusión" de las personas jurídicas de la jurisdicción de la Comisión y la Corte. Frente a esta exclusión, los autores de Los derechos humanos de las personas jurídicas. Titularidad de derechos y legitimación en el sistema interamericano ofrecen argumentos que de lege lata y de lege ferenda permitirían incluir a las personas jurídicas en el alcance de su jurisdicción. En otros términos, la obra trata, por un lado, sobre la cuestión de la adecuada protección en el seno del Sistema Interamericano de Derechos Humanos de las personas naturales que sufren lesiones como efecto conexo de vulneraciones a derechos de entes colectivos; $y$, por otro lado, sobre las personas jurídicas como sujetos titulares de derechos convencionales y legitimados para solicitar su tutela ante tribunales internacionales del mentado sistema.

El trabajo analiza pormenorizadamente toda la jurisprudencia de la Corte y de la Comisión Interamericana de Derechos Humanos respecto de la negación de la protección de las personas jurídicas al haber entendido — con avances y retrocesos históricos en su devenir- que el Pacto de San José de Costa Rica sólo protege al ser humano, dejando de lado a las personas jurídicas. De este modo, han negado de una u otra forma la participación de las personas morales como víctimas de violaciones de sus derechos humanos en esa sede internacional. Por otra parte, esa jurisprudencia pone de manifiesto que, como un efecto de la doctrina denegatoria de derechos sustanciales y de la tutela procesal a las personas jurídicas, las personas individuales relacionadas con un ente colectivo (como fundadores, miembros, socios, asociados, dueños, empleados, etc.) también han encontrado en los órganos del Sistema o bien una negativa o bien una protección incompleta cuando han sufrido un agravio en sus derechos como lesión manifiesta de violaciones directas a los derechos de las personas morales con las cuales se relacionan en tales caracteres.

En apretada síntesis, el andamiaje argumentativo a favor de la protección sustancial y procesal de las personas de existencia ideal en esa sede internacional, que propone el texto, puede esquematizarse de la siguiente manera:

1. La aplicación de dos rígidas reglas con un excesivo formalismo, a saber: la no legitimación de las personas jurídicas y el agotamiento de los recursos disponibles en sede nacional por parte de la víctima. Ambas han hecho, en la práctica, que en el continente americano haya graves vulneraciones a las libertades que no podrían ser denunciadas ante los organismos tuitivos de la Organización de Estados Americanos. Ello implica una retrogradación de tales entes morales, que son sujetos de derecho desde Roma hasta nuestros días, en sede nacional.

2. Paralelamente con lo anterior, tales agravios no podrían ser ventilados en juicio internacional ante la Comisión por las personas naturales que son sus víctimas secundarias o por conexidad, ya que en jurisdicción interna usualmente no fueron parte de los procesos. Mientras que el ente moral goza de protección interna, la 
persona física, en cambio, al no ser agraviada directa, no pudo ser parte en esos recursos internos, ni de manera solitaria ni en conjunto con la persona jurídica lesionada. En virtud de esto, la persona individual no habría agotado los recursos internos y por tanto no tendría derecho a accionar en busca de tutela ante los órganos interamericanos. Ello es reprochable desde el punto de vista internacional.

3. Si bien hubo diversos períodos en la evolución de las respuestas de la Comisión y de la Corte Interamericana a estos problemas, lo cierto es que en la actualidad la única posibilidad en que estos casos logren entrar al Sistema es mediante el camino de circunvalación que pasa por proteger los derechos de las personas humanas que integran los entes morales o que están relacionadas con ellos. Ello ofrece un grave incómodo a la defensa de tales derechos humanos que es menester simplificar, efectivizar y garantizar.

4. Hubo un período anterior a 1991, al menos desde 1978 a 1987, en el que la Comisión Interamericana de Derechos Humanos admitió a personas jurídicas como víctimas per se y sus fundamentos son aplicables en otros casos análogos, mutatis mutandis. Por otra parte, los casos del mencionado período se dieron bajo el régimen exclusivo de la Declaración Americana de los Derechos y Deberes del Hombre, pues en los respectivos países no estaba entonces vigente la Convención Americana sobre Derechos Humanos. Por ello a fortiori esa protección y esos fundamentos son aplicables por analogía al actual Sistema.

5. Una razonable interpretación literal de la Declaración Americana muestra que ella sí permite que las personas jurídicas sean titulares de los derechos que ella consagra, lo que está patente en los fundamentos de la jurisprudencia acogedora de la protección, en el período de 1978 a 1987, la que lógicamente es plenamente aplicable en tal sentido.

6. Es criticable la doctrina y jurisprudencia de la Comisión y de la Corte Interamericana respecto de una interpretación restringida del Artículo 1.2. de la Convención Americana, que entiende que de acuerdo a esa norma el Pacto de San José sólo protege a personas humanas. En esos casos, resueltos entre 1991 y 2001, tampoco se atendió las situaciones de las personas físicas afectadas por ser dueńas o por integrar una persona moral lesionada, puesto que no habían agotado los recursos de la jurisdicción interna. Los autores se explayan sobre esto al analizar ese período, caso por caso.

7. En un segundo período, desde 2001 a 2010, tales órganos internacionales acogieron violaciones a derechos de personas naturales víctimas indirectas de daños en procesos donde el lesionado directo era una persona jurídica. Se trataba de individuos relacionados con una persona moral afectada, a los que, para poder acceder al Sistema se les solicitó algunos requisitos formales restrictivos de la tutela a brindar. El daño, entonces, no se produce de manera directa sino indirecta, refleja u oblicua y por ende la protección fue limitada ya que, en cada uno de esos casos ambos órganos interamericanos exigieron que las personas físicas interesadas hubieran ejercido algunos de los recursos internos en cabeza propia, en solitario o acompañando las acciones o remedios que las personas jurídicas habían planteado. Ello es objetable por su limitación y por su artificiosidad, lo que deviene en indefensión internacional y por ende es menester corregir.

8. En un tercer período que va desde 2009 en adelante, se inaugura un criterio práctico para que se admitan casos donde hay personas jurídicas afectadas, al cual los 
autores han dado en llamar "principio de legitimación por conexidad en el daño". Se trata del reconocimiento claro y expreso de que las violaciones a los derechos de un ente colectivo pueden violar, por conexidad, los derechos de las personas físicas que reclaman amparo, que son las titulares de derechos protegidos por la Convención Americana sobre Derechos Humanos y por sus órganos de tutela. No admiten, entonces, a personas morales directamente como víctimas o presuntas víctimas en los procedimientos, sino a sus dueños, accionistas, miembros, trabajadores, asociados, etc. Este principio de conexidad en el daño ha servido, entre otros efectos, para eliminar el requisito del agotamiento de los recursos internos por parte de personas individuales integrantes de personas morales, en todos aquellos supuestos en los que esas personas físicas no fueron parte de los procesos en sede nacional, sino sólo el ente colectivo. La razón implícita de estos pronunciamientos es que, por la conexidad, al haberse discutido en los procedimientos domésticos la causa que produjo el daño a los derechos individuales, se satisfacen las finalidades que protege ese requisito. Estos fundamentos son legítimos para defender la tesis de los autores, pero adolecen del mismo carácter de limitación y artificiosidad que el período anteriormente mencionado.

9. Más allá de lo anterior, los autores descubren en el libro que existen varios leading cases que abarcan un período de más de diez años hasta la actualidad, que, bien leídos, muestran a las claras que tanto la Comisión como la Corte también protegieron directamente a una persona jurídica, lo que hicieron tanto en medidas cautelares como en medidas provisionales, tanto en recomendaciones en informes de fondo, como en sentencias sobre el fondo del caso, previniendo o reparando vulneraciones a personas jurídicas que eran conexas con violaciones a derechos de una persona física, a veces porque ésta era la manera de poder tutelar algún derecho de la persona natural, y en otras ocasiones sin siquiera tal necesidad ni finalidad. Y los autores observan que, en cada caso, aunque alguna jurisprudencia de la Corte — acotada a la discusión sobre un derecho_ diga que cuando habla de una persona jurídica se refiere a los individuos relacionados con ella, lo cierto es que lo que hizo — en esos casos — fue tomar decisiones atinentes de modo directo a la situación jurídica de personas jurídicas. En nuestra opinión, este aspecto muestra una sagaz apreciación de la jurisprudencia y opiniones de estos órganos internacionales.

10. El libro pone de manifiesto que es menester interpretar ampliamente el principio de conexidad entre la víctima y sus integrantes, evitando caer en una identidad de derechos conjuntos a proteger.

11. La obra desarrolla también una importante excepción a todo lo anterior: el caso de los pueblos indígenas y tribales, en cuyos casos se protegió a las comunidades en sí mismas, como legitimadas directas, reconociéndole la titularidad de derechos colectivos sin apelaciones a lesiones de manera oblicua a sus miembros. Ello denota una falta de coherencia entre lo resuelto sobre esas comunidades y sus derechos, en relación con lo que se afirma en general sobre la exclusividad en la tutela a personas individuales y el rechazo a toda protección a personas morales. Los fundamentos de las respectivas sentencias y opiniones son aplicables a todas las personas jurídicas, por analogía. Por ende, tal aplicación analógica debe ser puesta en acto y tal inconsistencia debe ser superada.

12. Los autores sostienen que el no admitir la tutela de personas morales por daños 
directos, por un lado, y el proteger limitadamente a las personas físicas que las integran, con obstáculos innecesarios o requerimientos complicados, por el otro, tiene como consecuencia que el Sistema Interamericano de Derechos Humanos acote inexplicablemente los derechos humanos individuales y colectivos, en aras de una interpretación restrictiva, estática, formalista y no sistemática de la Convención Americana. Por ende, es menester realizar una adecuada interpretación de la misma, tanto de lege lata como de lege ferenda.

13. Ellos proponen, en consecuencia, que en el Sistema Interamericano se admita abiertamente y de modo directo el binomio de la titularidad de derechos colectivos por personas morales y la legitimación procesal de las personas jurídicas como presuntas víctimas. Esto es posible mediante una relectura del Artículo 1.2. de la Convención, fundada en argumentos histórico-críticos, de lógica, lingüísticos, axiológicos, teleológicos y en un "no cerrarse" a una interpretación dinámica y evolutiva de esa norma. Entre esos argumentos se cuenta con el Artículo 1.2. de la $\mathrm{CADH}$ que ha querido que ningún ser humano sea dejado fuera de la categoría de las personas, pero sin pretender negar directamente todo derecho a las personas jurídicas. De hecho, a mayor abundamiento, la versión francesa del Pacto de San José de Costa Rica, que es una de las versiones oficiales, deja claro que ese artículo quiso obligar al reconocimiento de la personalidad a todos los seres humanos y no negarla a los entes colectivos.

14. Existen una serie de razones y de normas convencionales por las cuales el negar derechos y protección a las personas colectivas es contrario a las disposiciones de la Convención, de la Declaración Americana y de varios principios de Derecho Internacional, como el de igualdad y no discriminación, el pro homine o el de efecto útil de los tratados, así como los derechos al reconocimiento de la personalidad jurídica, de asociación y a la protección judicial efectiva, entre otros. Por ello es menester asegurar la vigencia de tales principios y derechos respecto de las personas jurídicas, a riesgo de cometer una palmaria injusticia formal y material.

15. Una de las razones sistemáticas en apoyo de esta tesis es el Protocolo de San Salvador, que reconoce esa protección y legitimación procesal a los sindicatos y entidades educativas, normativa que a juicio de los autores es análoga al Protocolo facultativo n. 1 al Convenio Europeo para acceder a la Corte Europea de Derechos Humanos y aplicable directamente, al menos, a los países que son parte del Protocolo americano.

16. Más allá del derecho positivo, los autores abundan en la teoría general de los derechos humanos, que avala la titularidad de derechos fundamentales por parte de personas jurídicas, con la consecuente necesidad de protegerlos. Entre ellos mencionan el derecho de libre asociación de los seres humanos integrantes de los entes morales, siendo que no tendría sentido que los humanos tengan menos derechos luego de asociarse que antes de hacerlo. Por ello, una persona jurídica es titular de derechos fundamentales (o "derechos humanos por analogía") como medio para lograr la efectiva realización de los derechos de las personas humanas que la integran y que actúan por ella.

17. El principio universal de responsabilidad de la persona jurídica — que hoy abarca hasta aspectos penales - implica como correlato un principio universal de titularidad de derechos —ubi poena, ibi ius - y que todo derecho sustancial es acreedor a un cauce procesal de tutela —ubi ius, ibi actio- . Esto ocurre paradig- 
máticamente en casos como los referidos a los derechos políticos y sindicales, las libertades de expresión, de educación y religiosa y en ocasiones la propiedad.

18. El libro se hace cargo de los fundamentos en contra de la postura que propone. Sostiene que el temor al colapso tribunalicio o a la desnaturalización del instituto preconizado que esta interpretación pudiera producir no debe encontrarse en la regla de exclusión de las personas jurídicas, fundada en la incompetencia ratione personae por las apuntadas razones y por cuanto la competencia ratione materiae permite a la Comisión Interamericana descartar aquellos casos no tutelados por la Convención Americana. De este modo se expanden las potencialidades de tutela del Sistema regional y queda sin mengua la selección de los casos a los que se abrirá la instancia, sin excluir a priori a ninguna víctima presunta.

19. En el campo del derecho comparado desarrollan los ejemplos de Estados Unidos, España y Alemania, cuyos ordenamientos domésticos admiten el reconocimiento de derechos fundamentales a las personas jurídicas. Los fundamentos de tales sistemas internos son aplicables al Sistema Interamericano de protección de derechos por analogía, lo que entendemos es justo desde el punto de vista formal y material.

20. El derecho comparado demuestra también cómo, a contrario sensu, negar el mencionado binomio titularidad-legitimación a las personas jurídicas implica la frustración de buena parte del contenido esencial de varios de los derechos fundamentales protegidos a nivel interno e internacional, que los autores detallan.

21. El otro gran sistema de protección regional, el Sistema Europeo de Derechos Humanos admite sin ambages a las personas jurídicas por así estar expresamente previsto sobre el derecho de propiedad en un protocolo sobre algunos nuevos derechos. Los autores ponen de manifiesto que, bien leído, el Protocolo de San Salvador debería tener los mismos efectos en el Sistema Interamericano que el Protocolo no. 1 europeo.

22. Por su parte, el Sistema del Comité de Derechos Humanos en el ámbito de la ONU, no admite en principio ese binomio respecto de las personas jurídicas, pero sí lo hace en ocasiones, respecto de las personas individuales que se vieron afectadas indirectamente por daños directos a la persona moral.

23. Por último, los autores desarrollan el caso de la libertad de expresión como aquél que, en la actualidad, constituye un arquetipo de derecho que en buena medida se ejerce a través de personas jurídicas, protegiendo de ese modo la libertad de información y la de opinión en las Américas, consagradas en el Artículo 13 de la Convención. En este sentido, la libertad de expresión es así especialmente pertinente y transcendente respecto del tema analizado pues se trata de una libertad estratégica para el funcionamiento democrático y para la protección de los otros derechos humanos. Así ha ocurrido en algunos informes de la Comisión y en sentencias de la Corte que han dictado medidas cautelares y provisionales para la protección de medios. Al caso paradigmático de los medios de comunicación dedican los autores el último capítulo de la obra.

En resumen, esta obra bien puede servir de base para un futuro promisorio más justo respecto de la defensa de los derechos sustanciales y procesales de las personas jurídicas, posibles víctimas de violaciones de derechos humanos en el ámbito internacional atendiendo a las actuales restricciones y limitaciones en ese sentido por parte de los órganos del Sistema interamericano, 
la Comisión y la Corte Interamericana. Estas libertades y derechos fundamentales, conforme lo apuntado ut supra, forman parte de la estructura democrática de las modernas sociedades del siglo XXI que es menester defender. La tesis de esta obra lo logra acabadamente, no sólo desde el punto de vista del derecho positivo, sino también desde el análisis de las cuestiones de justicia inherentes al tema.

Finalmente, las tesis apuntadas pueden permitir la protección más acabada de los sujetos de derecho de existencia ideal en el campo de la empresa y de las entidades sin fines de lucro, sectores económicos que, si bien pueden haber sido relegados en el pasado del Sistema Interamericano de Derechos Humanos, justifican la apertura de nuevos horizontes en esta materia, en base a los principios y normas del derecho interno e internacional, además de las cuestiones de justicia inherentes, como parte de un Sistema abierto a nuevos sectores económicos. 